Check for updates

Cite this: RSC Adv., 2019, 9, 15694

\title{
Comprehensive quali-quantitative profiling of neutral and sialylated $O$-glycome by mass spectrometry based on oligosaccharide metabolic engineering and isotopic labeling $\dagger$
}

\author{
Lijing Nan, ${ }^{a}$ Jiao Li, ${ }^{\text {ab }}$ Wanjun Jin, ${ }^{\text {ab }}$ Ming Wei, ${ }^{\text {ab }}$ Mengjun Tang, ${ }^{\text {ab }}$ Chengjian Wang, ${ }^{\text {ab }}$ \\ Guiping Gong, ${ }^{\text {ab }}$ Linjuan Huang, ${ }^{\text {ab }}$ Ying Zhang ${ }^{\star a}$ and Zhongfu Wang (D) *ab
}

Mass spectrometry (MS) analysis combined with stable isotopic labeling is of great importance for quantitatively profiling abnormal sialylated O-glycans associated with disease development, but technically hindered by the poor releasing efficiency of $O$-glycans from glycoprotein or the labile nature of sialic acid residues at glycans. Herein, we developed an isotopic precursor based metabolic amplification and labeling (IPMAL) technique for relative quantitative profiling of the repertoire $O$-glycans between normal and tumor cells by ESI-MS. Two groups of cells were incubated with peracetylated benzyl- $\alpha-N$-acetylgalactosamine $\left(\mathrm{Ac}_{3} \mathrm{GalNAc}-\alpha-\mathrm{Bn}^{\mathrm{d} 0}\right)$ or a heavy labeled peracetylated benzyl- $\alpha-N-$

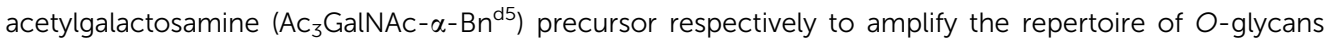
as $\mathrm{Bn}^{\mathrm{do} / \mathrm{d} 5}-\mathrm{O}$-glycans which could achieve the quantitative $\mathrm{O}$-glycome analysis by ESI-MS after derivatization. The established method demonstrates desirable feasibility, accuracy (relative error (RE) $\leq$ $4.20 \%$ ), reproducibility (coefficient of variation $(\mathrm{CV}) \leq 7.61 \%, n=3)$ and good quantitation linearity $\left(R^{2}>\right.$ $0.99, n=3$ ) for five Bn-O-glycans with 2 orders of magnitude. Finally, the method has been successfully applied to quantitative analysis of the repertoire $O$-glycome changes between normal human liver cell line L02 and human hepatoma cell line SMMC-7721. Moreover, the $\alpha-2,3 / 2,6$ sialic acid isomers of Bn$O$-glycans from these two cells have been further quantitatively distinguished when involved a sialic acid specific derivatization procedure.

Received 12th February 2019

Accepted 11th May 2019

DOI: $10.1039 / c 9 r a 01114 \mathrm{e}$

rsc.li/rsc-advances determination as well as sialic acid linkage specific identification of $O$-glycans expressed in normal and tumor cells will be beneficial for functional elucidation and diagnostic or prognostic purposes during disease development procedures as required in pathology or glycomics.

Mass spectrometry with high sensitivity and resolution, has played an important role in the structural analysis of glycoconjugates and quantitative analysis of glycans changes between two samples using "light" and "heavy" stable isotopic labels. ${ }^{12-14}$ One common method employing $\mathrm{NaOH}$ solution to release and instantaneously reduce the aldehyde ends at $O$ glycans with "light" and "heavy" isotopic reagents, $\mathrm{NaBH}_{4}$ and $\mathrm{NaBD}_{4}$, respectively, has been widely used for MS quantification profiling of $O$-glycome changes between two samples. ${ }^{15}$ Besides, the $O$-glycans derived from two samples could be permethylated with ${ }^{12} \mathrm{CH}_{3} \mathrm{I} /{ }^{13} \mathrm{CH}_{3} \mathrm{I}$ or $\mathrm{CD}_{3} \mathrm{I} / \mathrm{CH}_{3} \mathrm{I}$ isotopic labeling strategy to achieve the quantitation determination of overall $O$-glycome by MS. ${ }^{16,17}$ Wang et al. ${ }^{18}$ have developed an one-pot $O$-glycans releasing and d0/d5-PMP isotope labeling assay for qualitative and quantitative profiling of $O$-glycans from glycoproteins by MS. Recently, Kudelka had reported an isotopic labeling with cellular $O$-glycome reporter/amplification (ICORA) for
${ }^{a}$ Key Laboratory of Resource Biology and Biotechnology in Western China, Ministry of Education and Provincial Key Laboratory of Biotechnology, College of Life Sciences, Northwest University, Xi'an 710069, P. R. China. E-mail: wangzhf@nwu.edu.cn ${ }^{b}$ College of Food Science and Technology, Northwest University, Xi'an 710069, P. R. China

$\dagger$ Electronic supplementary information (ESI) available. See DOI: 10.1039/c9ra01114e 
comparative $O$-glycomics of cultured cells by MS. ${ }^{19}$ Despite all progress in quantification determination of $O$-glycans in glycomics studies, further investigation is needed to be conducted to improve/resolve these corresponding defects, such as misunderstanding of natural peaks of glycans with the isotopelabeled one due to the small molecular weight difference (1 Da), lack of universal hydrolytic enzyme used for effectively releasing of all $O$-glycans from glycoproteins, large amounts of glycoproteins used which might be not practicable for biological sample analysis and difficulty in quali-quantitative identification of $\alpha-2,3 / 2,6$ sialic acid terminal ends of $O$-glycan isomers by MS. ${ }^{20-22}$

Although mass spectrometry has become an important tool to determine glycan structures, poor ionization of native glycans or sialic acids signal loss at glycans were easily happen when without a derivatization procedure..$^{23,24}$ Moreover, MS and/or MS/ MS glycomics profiling might face challenge in quali-quantitative determination of $\alpha-2,3 / 2,6$-linked sialic acids at the terminal ends of glycan isomers. ${ }^{25}$ Due to the pathological importance of the $O$ glycan terminal sialic acids, ${ }^{26}$ it is of great significance to establish a high-throughput and effective method for MS-based quantification of overall neutral and sialylated $O$-glycans with linkage specificity between normal and tumor cells.

In our previous work, a sialic acid specific derivatization combined with Girard's reagent T (GT) on-target labeling has been exploited for MS-based linkage specific determination of sialic acids at kinds of glycans. ${ }^{27}$ Importantly, it has been reported recently the dimethylamidation is compatible with traditional permethylation to achieve the linkage-specific identification of sialic acids at $N$-glycan ends by MS. ${ }^{28}$ These research findings inspire us to utilize the strengths of chemical derivatization and oligosaccharide metabolic engineering and isotopic labeling strategy, to develop an isotopic precursor based metabolic amplification and labeling (IPMAL) assay for quali-quantitatively profiling of sialic acids linkage specificity of $O$-glycans between normal and tumor cells by MS. ${ }^{29}$

Within our IPMAL strategy, normal and tumor cells were respectively incubated with $\mathrm{Ac}_{3}$ GalNAc- $\alpha-\mathrm{Bn}^{\mathrm{d} 0}$ and $\mathrm{Ac}_{3}$ GalNAc- $\alpha-$ $\mathrm{Bn}^{\mathrm{d} 5}$ (5 Da mass difference) substrates, which could enter cells and be used by enzymes in Golgi to amplify the repertoire of $O$-glycome to be Bn-O-glycans. ${ }^{19,29}$ Comprehensive quali-quantitative profiling of Bn-O-glycans from two cells after 1 : 1 mixing could be achieved by MS, as illustrated in Scheme 1. We have evaluated the method in terms of feasibility, reproducibility, accuracy and linear properties. The established assay has been applied to qualiquantitatively profile and determine the $O$-glycans between normal human liver cell line L02 and human hepatoma cell line SMMC-7721 after permethylation. ${ }^{30,31}$ Furthermore, the whole $O$ glycan isomers with/without $\alpha-2,3 / 2,6$ sialic acid ends have been quali-quantitatively distinguished when a sialic acid specific derivatization procedure was involved. ${ }^{28}$

\section{Materials and methods}

\section{Chemicals and materials}

$N$-Acetyl-D-galactosamine, 1,2-dichloroethane, copper trifluoromethanesulfonate $\left(\mathrm{Cu}(\mathrm{OTf})_{2}\right)$, benzyl alcohol, 4-nitrobenzyl
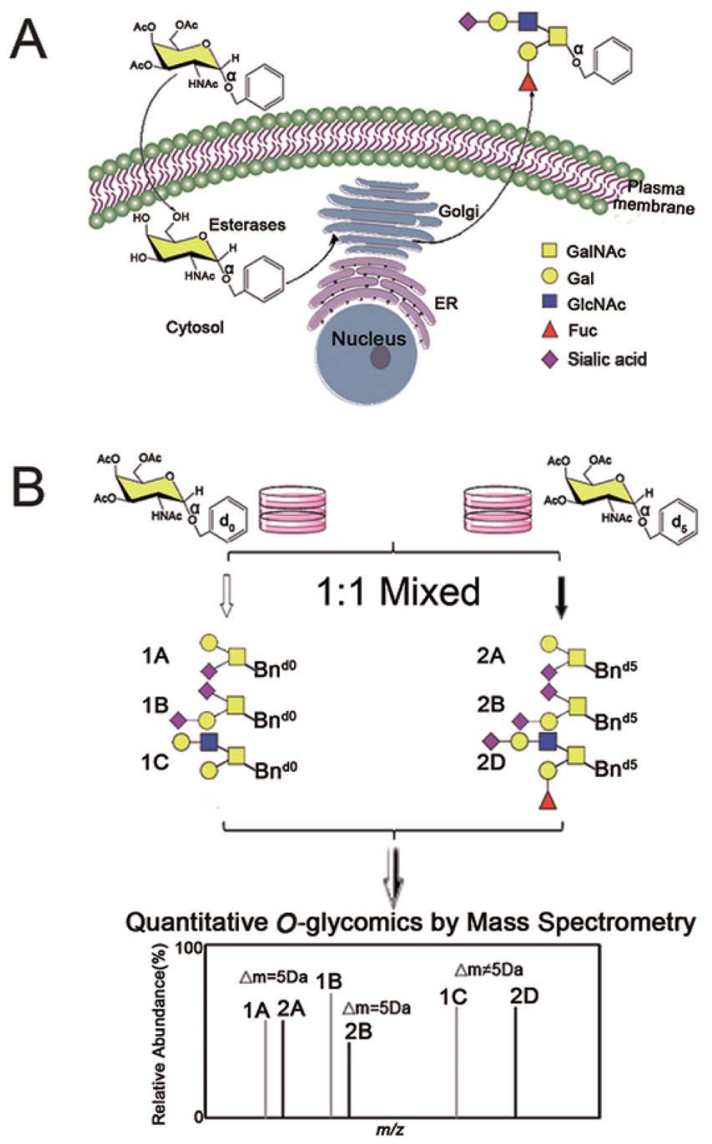

Scheme 1 Isotopic precursor based metabolic amplification and labeling (IPMAL) strategy for quantitatively profiling the repertoire of $O$-glycans between normal and tumor cells. Structure formulas: yellow square, $\mathrm{N}$-acetylgalactosamine (GalNAc); blue square, $\mathrm{N}$-acetylglucosamine (GalNAc); yellow circle, galactose (Gal); red triangle, fucose (Fuc); purple diamond, sialic acid ( $N$-acetylneuraminic acid, Neu5Ac; $N$-glycolylneuraminic acid, Neu5Gc).

alcohol, dimethylamine hydrochloride, 1-ethyl-3-(3(dimethylamino)propyl)-carbodiimide (EDC) hydrochloride and 1-hydroxybenzotriazole (HOBt) monohydrate were purchased from Aladdin Inc. (Shanghai, China). Dimethyl sulfoxide, benzyl2,3,4,5,6-d5 alcohol and 4-ethynylbenzyl alcohol were purchased from Sigma-Aldrich (St. Louis, MO, USA). High-glucose Dulbecco's modified Eagle's medium (DMEM) was purchased from HyClone (Logan, UT, USA). Amicon Ultra $4 \mathrm{~mL}$ centrifugal filters (10 kDa) were purchased from Millipore (Bedford, MA, USA). $3^{\prime}$-Sialyllactose (3'-SL, $\alpha 2,3$-linked sialic acid) and 6'-sialyllactose (6'-SL, $\alpha 2,6$ linked sialic acid) were purchased from Carbosynth (Compton, U.K.). Sep-Pak C18 (3 cc) solid phase extraction (SPE) cartridges were obtained from Water Corporation (Milford, MA, USA). Human hepatoma cells SMMC-7721 and human normal liver cells L02 cell lines were purchased from Shanghai cell bank, Chinese Academy of Sciences. ${ }^{1} \mathrm{H}$ and ${ }^{13} \mathrm{C}$ NMR spectra were recorded with Bruker AC-600 spectrometers using $\mathrm{CDCl}_{3}$ as solvent. Mass spectra were measured under a Thermo Fisher Scientific LTQ Orbitrap XL spectrometer. The chemical reaction was monitored by thin layer chromatography (silica gel, $25 \mu \mathrm{m}$ layer thickness) and detected by a UV lamp (254 nm) combined with sulfuric acid-lichen phenol staining. All of these reagents were of analytical grade. 


\section{Synthesis of $O$-glycan precursors $\mathrm{Ac}_{3} \mathrm{GalNAc}-\alpha-\mathrm{Bn}^{\mathrm{do}}$ and} $\mathrm{Ac}_{3}$ GalNAc- $\alpha-\mathrm{Bn}^{\mathrm{d} 5}$

Synthesis of $O$-glycan precursors were carried out according to a reported procedure with minor modification. ${ }^{32-34}$ To a solution of glycosamine pentaacetates $(200 \mathrm{mg}, 0.514 \mathrm{mmol})$ in dry 1,2dichloroethane $(10 \mathrm{~mL})$, anhydrous $\mathrm{Cu}(\mathrm{OTf})_{2}(0.15$ equiv.) and d0-benzyl alcohol (4 equiv.) or heavy labeled benzyl alcohol (benzyl-2,3,4,5,6-d5 alcohol, 4 equiv.) were added. The reaction mixture was stirred vigorously under an $\mathrm{N}_{2}$ atmosphere reflux at $130{ }^{\circ} \mathrm{C}$ for $6 \mathrm{~h}$. When the reaction was completed, the saturated $\mathrm{NaHCO}_{3}$ aqueous solution was added to the reaction mixture to stop the reaction. The organic layer was totally layered after stirring. The collected organic layer was concentrated under the reduced pressure after washing with water twice. The concentrated organic residues were concentrated and loaded onto silica gel column separation using petroleum ether-EtOAc $(1: 1$ or other ratios based on TLC separation result) as mobile phase to acquire the desired product $\mathrm{Ac}_{3}$ GalNAc- $\alpha-\mathrm{Bn}^{\mathrm{d} 0}\left(R_{\mathrm{f}}=0.75\right.$, $161.77 \mathrm{mg}, 72 \%)$ or $\mathrm{Ac}_{3}$ GalNAc- $\alpha-\mathrm{Bn}^{\mathrm{d} 5}\left(R_{\mathrm{f}}=0.75,161.35 \mathrm{mg}\right.$, $71 \%$ ), which were further confirmed by MS and NMR data, as presented in Fig. $1 \mathrm{~B}$ and $\mathrm{S} 1 \mathrm{~A}-\mathrm{D}$ (ESI $\dagger$ file).

$\mathrm{Ac}_{3}$ GalNAc- $\alpha-\mathrm{Bn}^{\mathrm{d} 0}$, purity $98.6 \%$ (HPLC); ${ }^{1} \mathrm{H}$ NMR $(600 \mathrm{MHz}$, $\left.\mathrm{CDCl}_{3}\right), \delta 7.37(\mathrm{~d}, J=7.5 \mathrm{~Hz}, 2 \mathrm{H}), 7.31(\mathrm{~d}, J=6.8 \mathrm{~Hz}, 1 \mathrm{H}), 7.26(\mathrm{~s}$, $1 \mathrm{H}), 5.58(\mathrm{~d}, J=9.7 \mathrm{~Hz}, 1 \mathrm{H}), 5.38$ (d, $J=2.5 \mathrm{~Hz}, 1 \mathrm{H}), 5.17$ (dd, $J=$ 11.3, $3.2 \mathrm{~Hz}, 1 \mathrm{H}), 4.97$ (d, $J=3.6 \mathrm{~Hz}, 1 \mathrm{H}), 4.72(\mathrm{~d}, J=11.7 \mathrm{~Hz}$, $1 \mathrm{H}), 4.61-4.57(\mathrm{~m}, 1 \mathrm{H}), 4.49$ (d, $J=11.7 \mathrm{~Hz}, 1 \mathrm{H}), 4.21$ (s, 1H), 4.09 (dd, $J=18.6,6.6 \mathrm{~Hz}, 2 \mathrm{H}), 2.16$ (s, 2H), 2.05 (s, 2H), 1.98 (s, 2H), 1.90 (s, 3H). ${ }^{13} \mathrm{C}$ NMR (151 MHz, $\left.\mathrm{CDCl}_{3}\right) \delta$ 173.59, 173.09, 173.02, 172.63, 139.20, 131.35, 131.04, 130.89, 99.63, 79.90, 79.68, 79.47, 72.77, 71.06, 70.00, 69.58, 64.56, 50.34, 25.95, 23.43, 23.40. ESI-MS: calcd for $\mathrm{C}_{21} \mathrm{H}_{27} \mathrm{NO}_{9},[\mathrm{M}+\mathrm{Na}]^{+} m / z$ 460.35, found $m / z 460.08$.

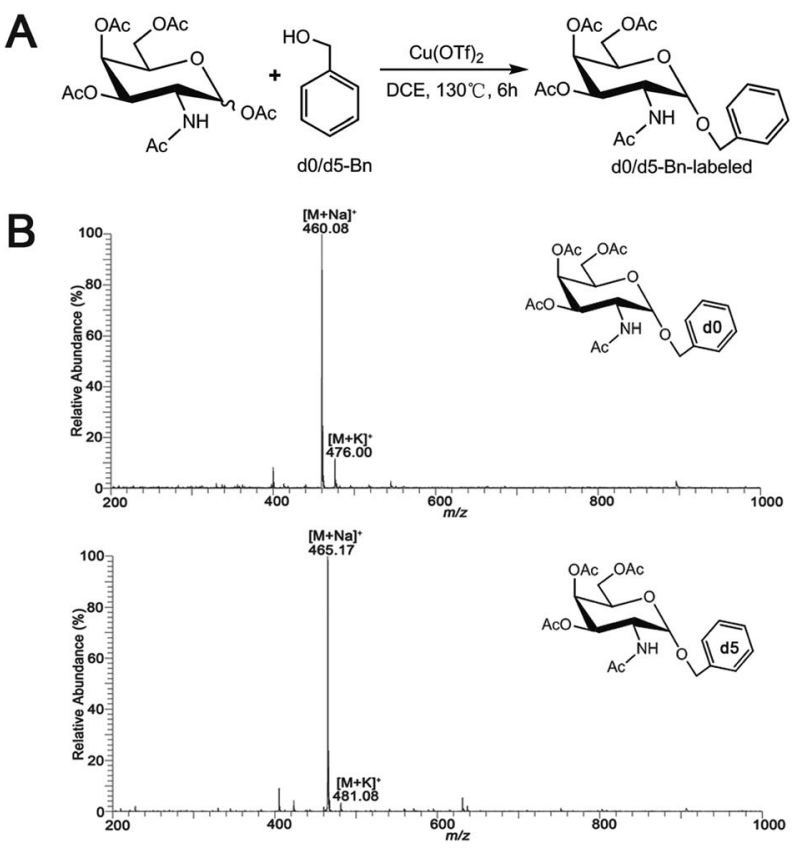

Fig. 1 (A) Synthetic scheme for $\mathrm{Ac}_{3} \mathrm{GalNAc}-\boldsymbol{\alpha}-\mathrm{Bn}$ precursor and (B) ESI-MS spectrum of the synthesized $A c_{3} G a l N A c-\alpha-B n^{d 0}$ and $A c_{3}-$ GalNAc- $\alpha-B n^{\mathrm{d} 5}$.
$\mathrm{Ac}_{3}$ GalNAc- $\alpha-\mathrm{Bn}^{\mathrm{d} 5}$, purity $97.8 \%$ (HPLC); ${ }^{1} \mathrm{H}$ NMR $(600 \mathrm{MHz}$, $\left.\mathrm{CDCl}_{3}\right), \delta 7.26(\mathrm{~s}, 6 \mathrm{H}), 5.56(\mathrm{~d}, J=9.6 \mathrm{~Hz}, 1 \mathrm{H}), 5.37(\mathrm{t}, J=9.8 \mathrm{~Hz}$, $1 \mathrm{H}), 5.18(\mathrm{dd}, J=11.3,3.1 \mathrm{~Hz}, 1 \mathrm{H}), 4.98(\mathrm{~d}, J=3.5 \mathrm{~Hz}, 1 \mathrm{H}), 4.72$ $(\mathrm{d}, J=11.7 \mathrm{~Hz}, 1 \mathrm{H}), 4.64-4.53(\mathrm{~m}, 1 \mathrm{H}), 4.50(\mathrm{~d}, J=11.7 \mathrm{~Hz}, 1 \mathrm{H})$, $4.22(\mathrm{t}, J=6.4 \mathrm{~Hz}, 2 \mathrm{H}), 4.10(\mathrm{~m}, 2 \mathrm{H}), 2.16(\mathrm{~s}, 3 \mathrm{H}), 2.06(\mathrm{~d}, J=$ $2.2 \mathrm{~Hz}, 3 \mathrm{H}), 1.95(\mathrm{~s}, 2 \mathrm{H}), 1.90(\mathrm{~s}, 3 \mathrm{H}) .{ }^{13} \mathrm{C} \mathrm{NMR}\left(151 \mathrm{MHz}, \mathrm{CDCl}_{3}\right)$ $\delta$ 173.56, 173.04, 172.97, 172.59, 102.31, 99.65, 79.87, 79.66, 79.45, 77.12, 72.72, 71.09, 70.02, 69.60, 64.55, 63.03, 50.39, 25.92, 23.69, 23.40, 23.33. ESI-MS: calcd for $\mathrm{C}_{21} \mathrm{H}_{32} \mathrm{NO}_{9}[\mathrm{M}+$ $\mathrm{Na}]^{+} m / z$ 465.08, found $m / z 465.17$.

\section{Cell culture}

Cell culture was carried out according to the reported procedure. ${ }^{35}$ SMMC-7721 and L02 cells were cultured with $10 \mathrm{~mL}$ DMEM medium containing $10 \%$ (by volume) fetal bovine serum and $100 \mathrm{U} \mathrm{mL}^{-1}$ penicillin-streptomycin mix. Cells were kept in an incubator at $37{ }^{\circ} \mathrm{C}, 5 \% \mathrm{CO}_{2}$ and $95 \%$ (volume fraction) airsaturated humidity. When the cell density was increased to $80 \%$ (cells $2 \times 10^{7}$ ), the medium with $10 \%$ fetal bovine serum was replaced with medium containing $8 \%$ (volume fraction) fetal bovine serum. Then $\mathrm{Ac}_{3}$ GalNAc- $\alpha$-Bn $(100 \mu \mathrm{M})$ was added to medium and kept for further three days.

\section{Acquisition and purification of Bn-O-glycans}

Acquisition and purification of Bn-O-glycans were carried out according to reported procedure with minor modification. ${ }^{29}$ After three days of culture, the culture medium was collected and filtered through a $10 \mathrm{kDa}$ ultrafiltration membrane $(2500 \mathrm{~g}$, $30 \mathrm{~min})$. The filtered solution was purified through a C18 cartridge (200 mg/4 mL) according to the following procedure. The column was equilibrated with $4 \mathrm{~mL}$ of acetonitrile, $8 \mathrm{~mL}$ of $50 \%(\mathrm{v} / \mathrm{v})$ acetonitrile and $10 \mathrm{~mL}$ of $0.1 \%(\mathrm{v} / \mathrm{v})$ trifluoracetic acid (TFA). Then the filtered media was loaded onto the column and washed with $2 \mathrm{~mL}$ of $0.1 \%(\mathrm{v} / \mathrm{v})$ trifluoracetic acid (TFA) four times. Bn-O-glycans were then eluted with $3 \mathrm{~mL}$ of $50 \%(\mathrm{v} / \mathrm{v})$ acetonitrile containing $0.1 \%$ TFA. The purified sample was collected and lyophilized to dry.

\section{General permethylation of $\mathrm{Bn}-\mathrm{O}$-glycans}

General permethylation of $O$-glycan samples was carried out according to the reported procedures with minor modification. ${ }^{30,31}$ The dried sample was dissolved in $300 \mu \mathrm{L}$ DMSO-NaOH suspension and $75 \mu \mathrm{L} \mathrm{CH} \mathrm{CH}_{3} \mathrm{I}$ mixture. After shaking $30 \mathrm{~min}$ in dark, $500 \mu \mathrm{L}$ water was added into sample to quench the reaction. Then $500 \mu \mathrm{L}$ dichloromethane was added. The supernatant was then partitioned between water and dichloromethane. The organic layer was washed with $500 \mu \mathrm{L}$ water twice, dried and redissolved in $200 \mu \mathrm{L} 50 \%$ methanol for further MS analysis.

\section{The whole sialic acid specific derivatization procedure for Bn- $O$-glycans}

The whole derivatization procedure has two steps, including linkage specific derivatization of sialic acid and general permethylation. Linkage specific derivatization of sialic acid was conducted according to the previous references with minor 
modification..$^{28,36} 25 \mu \mathrm{L}$ of $500 \mathrm{mM}$ 1-hydroxybenzotriazole (HOBt, dissolved in DMSO), $25 \mu \mathrm{L}$ of $250 \mathrm{mM}$ 1-ethyl-3-(3dimethylaminopropyl) carbodiimide hydrochloride (EDC, dissolved in DMSO) and $25 \mu \mathrm{L}$ of $250 \mathrm{mM}$ dimethylamine dissolved in DMSO, were added to the dried glycan sample ( 5 pmol to 10 $\mathrm{nmol}$ ) and incubated at $60{ }^{\circ} \mathrm{C}$ for $1 \mathrm{~h}$. The excess dimethyamine was evaporated in a Speed Vac at $60{ }^{\circ} \mathrm{C}$ for $20 \mathrm{~min}$. Then the sample was treated with $200 \mu \mathrm{L}$ of $\mathrm{NaOH}-\mathrm{DMSO}$ slurry and 100 $\mu \mathrm{L}$ of methyl iodide for $30 \mathrm{~min}$ with agitation at room temperature. The reaction was terminated by adding $800 \mu \mathrm{L}$ of water. Subsequently, $200 \mu \mathrm{L}$ of dichloromethane was added. The mixture was stirred and centrifuged to facilitate partitioning. The top aqueous layer was then removed, while the dichloromethane layer was washed with $1 \mathrm{~mL}$ water three times additionally. Then the organic layer was dried and submitted to the general permethylation procedure as described above.

\section{Feasibility evaluation of the assay}

Two groups of human hepatoma cells SMMC-7721 cells were parallelly cultured with $100 \mu \mathrm{M} \mathrm{Ac} \mathrm{C}_{3}$ GalNAc- $\alpha-\mathrm{Bn}^{\mathrm{d} 0}$ and $\mathrm{Ac}_{3^{-}}$ GalNAc- $\alpha-\mathrm{Bn}^{\mathrm{d} 5}$, respectively, for 3 days. Both cell media was collected and mixed at a ratio of $1: 1$. The mixed culture medium was then submitted to purification, permethylation and MS-based quantification analysis.

\section{Evaluation the linearity of the assay}

Two groups of SMMC-7721 cells were in parallel cultured with $100 \mu \mathrm{M} \mathrm{Ac} c_{3}$ GalNAc- $\alpha-\mathrm{Bn}^{\mathrm{d} 0}$ and $\mathrm{Ac}_{3}$ GalNAc- $\alpha-\mathrm{Bn}^{\mathrm{d} 5}$, respectively, for 3 days. The media from two conditions was mixed in a gradient ratios $(10: 1,7.5: 1,5: 1,2.5: 1,1: 1,1: 2.5,1: 5$, $1: 7.5$ and $1: 10, n=3$ ). Linearity evaluation of the assay was plotted using relative intensities ratios of major $O$-glycan pair peaks observed in MS spectra as the $y$-axis versus the adding linear gradient ratios $(10: 1,7.5: 1,5: 1,2.5: 1,1: 1,1: 2.5$, $1: 5,1: 7.5$ and $1: 10$ ) of $O$-glycans mixture as the $x$-axis. The calibration graphs for the assay were calculated by the equation: $y=m x+c$.

\section{Statistical analysis}

Results of all experiments performed for the relative intensity ratios of peak pairs in MS-based relative quantification in triplicates were indicated by mean \pm SD. Data was analyzed by oneway analysis of variance (ANOVA) using SPSS 16.0. Statistical differences were determined using a two-tailed Student's $t$-test, with $p<0.05$ indicating statistical significance.

\section{ESI-MS and MS/MS conditions}

The ESI-MS and MS/MS data was acquired with an LTQ XL iontrap mass spectrometer equipped with an electrospray ion (ESI) source (Thermo Scientific, USA). The samples were injected into electrospray ion source via a $2 \mu \mathrm{L}$ Rheodyne loop in a stream of $50 \%$ methanol at a flow rate of $100 \mu \mathrm{L} \mathrm{min}^{-1}$. The spray voltage was set at $4000 \mathrm{~V}$, with a sheath gas (nitrogen gas) flow rate of 20 arb, an auxiliary gas (nitrogen gas) flow rate of 5.0 arb, a capillary voltage of $37 \mathrm{~V}$, a tube lens voltage of $250 \mathrm{~V}$, and a capillary temperature of $300{ }^{\circ} \mathrm{C}$, positive ion mode scan, scan range is $\mathrm{m} / \mathrm{z}$ 200-2000. MS/MS analysis was carried out using helium (He) as the collision gas, a normalized collision energy degree of 35$45 \%$ and an isotope width of $m / z 2.00$. The ESI-MS and MS/MS data were acquired with LTQ Tune software Xcalibur (Thermo). Other parameters were acquiescent.

\section{Results and discussions}

Kudelka recently have developed an isotopic labeling with cellular $O$-glycome reporter/amplification (ICORA) strategy, which employed two $O$-glycan precursors, $\mathrm{Ac}_{3} \mathrm{GalNAc}^{-\mathrm{Bn}^{\mathrm{H} 7}}$ and $\mathrm{Ac}_{3}$ GalNAc-Bn ${ }^{\mathrm{D} 7} \cdot{ }^{19}$ The assay provides a useful tool for exploring the dynamic changes in $O$-glycan between two cells. However, the incapability of determination $\alpha 2,3 / 2,6$-sialylated $O$-glycan isomers with linkage specificity by MS and/or MS/MS might be limit its application at some extent. Moreover, dimethylamidation has been used to distinguish $\alpha$-2,3/2,6-linked sialic acids at $\mathrm{N}$-glycans, which is compatible with common permethylation. ${ }^{28}$ Herein, an innovative strategy for the first MSbased quali-quantitative profiling and linkage-specific identification of $O$-glycans with or without sialic acids ends through isotopic precursor based metabolic amplification and labeling (IPMAL) assay could be achieved, when involved the sialic acid specific derivatization. ${ }^{28}$

\section{Principle of the assay}

A schematic procedure for quantitative profiling of the repertoire of $O$-glycome through isotopic precursor based metabolic amplification and labeling (IPMAL) assay, is depicted in Scheme 1. We designed a novel strategy for rapid synthesis of the normal and/or heavy labeled precursors, as depicted in Fig. 1A. One step $O$-glycosylation of glycosamine pentaacetates with a normal or heavy labeled benzyl alcohol could afford the final products $\mathrm{Ac}_{3}$ GalNAc- $\alpha-\mathrm{Bn}^{\mathrm{d} 0}$ or $\mathrm{Ac}_{3}$ GalNAc- $\alpha-\mathrm{Bn}^{\mathrm{d} 5}$ in good yields $(>70 \%)$, as confirmed by NMR (Fig. S1A-D, ${ }^{1} \mathrm{H}$ and ${ }^{13} \mathrm{C}$ NMR, $\mathrm{ESI} \dagger$ file) and ESI-MS (Fig. 1B). Both neutral and sialylated $O$ glycans could be amplified through oligosaccharide metabolic engineering in the presence of precursors $\mathrm{Ac}_{3} \mathrm{GalNAc}-\alpha-\mathrm{Bn}^{\mathrm{d} 0}$ or $\mathrm{Ac}_{3}$ GalNAc- $\alpha-\mathrm{Bn}^{\mathrm{d} 5}$ (5 Da mass difference) within two cells. Then quali-quantitative profiling of $O$-glycans as well as sialic acid linkage specific characterization of $O$-glycans could be achieved by MS and MS/MS when involved a permethylation ${ }^{29}$ or the sialic acid specific derivatization procedure, ${ }^{28}$ as illustrated in Fig. S2 (ESI† file).

\section{Feasibility of the assay}

Two groups of SMMC-7721 cells in parallel were incubated with equal molar amounts of $\mathrm{Ac}_{3}$ GalNAc- $\alpha-\mathrm{Bn}^{\mathrm{d} 0}$ and $\mathrm{Ac}_{3}$ GalNAc- $\alpha-$ $\mathrm{Bn}^{\mathrm{d} 5} \mathrm{O}$-glycan precursors (5 Da mass difference) respectively, to amplify the whole $O$-glycans. Two groups of the amplified $O$ glycans were mixed in 1:1 ratio and submitted to permethylation. After direct permethylation, ESI-MS analysis of $\mathrm{Bn}^{\mathrm{do} / \mathrm{d} 5}$-O-glycans was illustrated in Fig. 2A. Ten pairs of the $\mathrm{Bn}^{\mathrm{do} / \mathrm{d} 5}$-O-glycans peaks with signals at $\mathrm{m} / \mathrm{z} 955.25 / 960.33$, $1200.33 / 1205.33$, 1316.33/1321.33, 1404.42/1409.42, 1561.33/ 


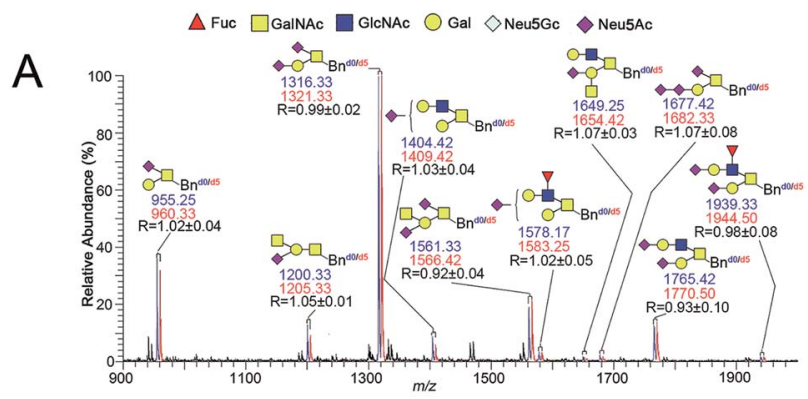

B

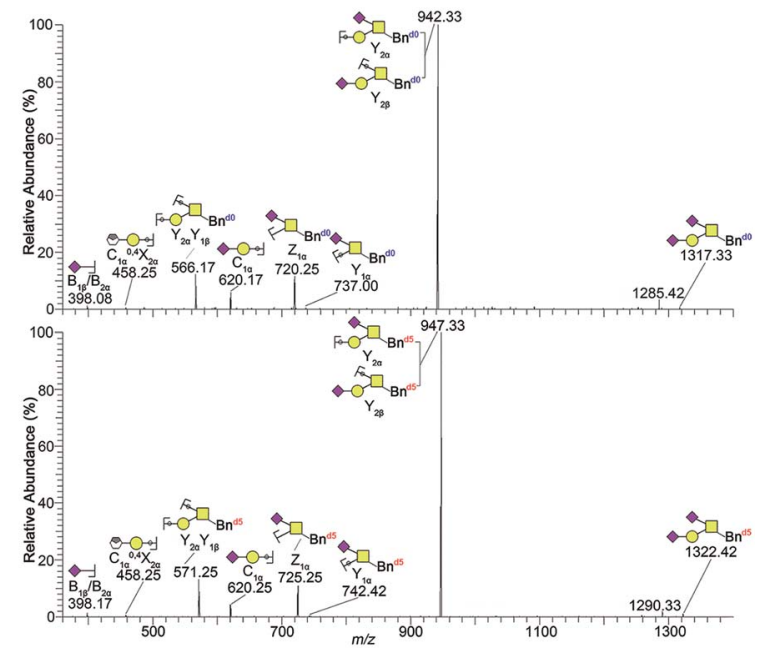

Fig. 2 (A) ESI-MS spectra profile of the $1: 1$ mixture of $\mathrm{Bn}^{\mathrm{dO}}-\mathrm{O}$-glycans (blue) and $\mathrm{Bn}^{\mathrm{d} 5}-\mathrm{O}$-glycans (red) from SMMC-7721 cells and (B) comparative sequencing of $\mathrm{Bn}^{\mathrm{d} / \mathrm{d} 5}$ - $\mathrm{O}$-glycans from SMMC-7721 by ESI-MS/MS. Each peak was fragmented by CID, respectively. Structure formulas: yellow square, $N$-acetylgalactosamine (GalNAc); blue square, $N$-acetylglucosamine (GalNAc); yellow circle, galactose (Gal); red triangle, fucose (Fuc); purple diamond, sialic acid (Neu5Ac); gray diamond, sialic acid (Neu5Gc).

1566.42, 1578.17/1583.25, 1649.25/1654.42, 1677.42/1682.33, 1765.42/1770.50 and 1939.33/1944.50 ([M + Na $]^{+}$adducts $)$were observed in MS profile. Structural characterizations of one pair of $O$-glycan peaks with signals at $\mathrm{m} / \mathrm{z} 1316.33 / 1321.33$ and other nine pairs of $O$-glycan peaks were achieved by ESI-MS/MS fragmentation in Fig. 2B and S3A-I, $\uparrow$ correspondingly. According to the MS data $(n=3)$, the $R$ values (the intensity ratio of the $\mathrm{Bn}^{\mathrm{do}}$ $O$-glycan to $\mathrm{Bn}^{\mathrm{d} 5}$-O-glycan) of each set of peaks were $1.02,1.05$, $0.99,1.03,0.92,1.02,1.07,1.07,0.93$ and 0.98 , which afforded an averaged $R$ value of 1.01 that was very close to the theoretical ratio of 1.0, demonstrating the good feasibility and reliability of the established method for relative quantitative analysis of $O$ glycans in two cells.

\section{Linearity and accuracy verification of the assay}

Linearity of five major pairs of $\mathrm{Bn}^{\mathrm{do} / \mathrm{d} 5}$-O-glycans peaks with signals at $m / z$ 955.25/960.33, 1200.33/1205.33, 1316.33/1321.33, 1561.33/1566.42 and 1765.42/1770.50 ([M + Na $]^{+}$adducts) were plotted according to their relative intensities ratios in the positive mode ESI-MS spectra versus the adding gradient ratios of $O$-glycans mixture $(10: 1,7.5: 1,5: 1,2.5: 1,1: 1,1: 2.5$, $1: 5,1: 7.5$ and $1: 10, n=3$ ), as shown in Fig. 3. The experiment revealed a desirable linear dependency between the observed relative intensities ratios of five major peaks of $O$ glycans in two groups of SMMC-7721 cells by MS and concentration ratios of the two samples, with the correlation coefficient being $\geq 0.99$ in all cases $(n=3$, Table 1$)$. The assay clearly presented a desirable linearity with a 100 folds linear dynamic range for sample measurements.

Clearly, the observed MS intensity ratios were very identical to the theoretical molar ratios as well as the samples amount ratios, as listed in Table 1 . Moreover, these average ratio data illustrated the averaged CVs (coefficients of variation) values (4.72, 4.07, 4.74, 6.76 and $7.61 \%, n=3$ ) lower than $8 \%$, demonstrating the desirable reproducibility and precision of the established method, after repeating the experiment in triplicate.

The accuracy of the method was evaluated by the measured ratios of $\mathrm{d} 0 / \mathrm{d} 5$-Bn-labeled $O$-glycans versus the theoretical ratios of d0/d5-Bn-labeled $O$-glycans to give some relative errors (REs).
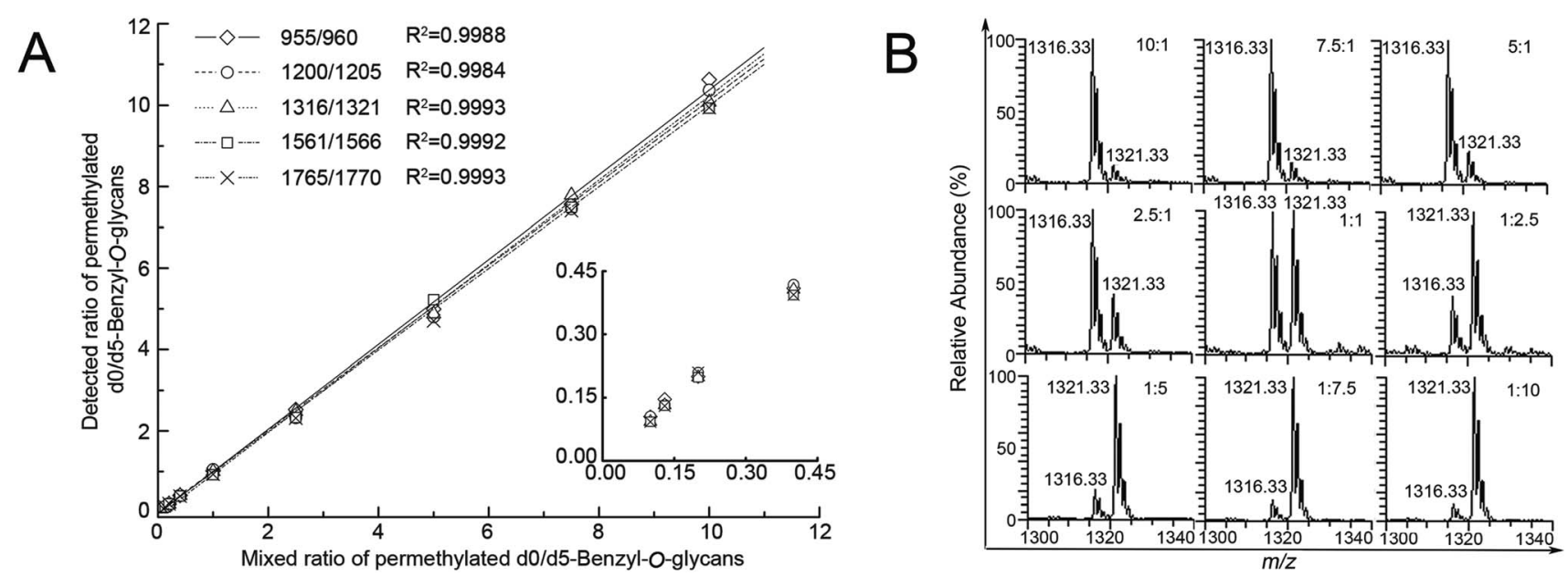

Fig. 3 (A) The linearity graph of the observed ESI-MS peak abundance ratios of $\mathrm{Bn}^{\mathrm{dO}}$-O-glycans to $\mathrm{Bn}^{\mathrm{d} 5}$ - $\mathrm{O}$-glycans versus the added ratios of $\mathrm{Bn}^{\mathrm{dO}}-\mathrm{O}$-glycans to $\mathrm{Bn}^{\mathrm{d5}}-\mathrm{O}$-glycans and (B) ESI-MS peak abundance ratios of one random pair peaks $(\mathrm{m} / \mathrm{z} 1316.33 / 1321.33)$ of $\mathrm{Bn} \mathrm{dO}_{-}-\mathrm{O}$-glycans to $\mathrm{Bn}^{\mathrm{d5}}$-O-glycans versus the added ratios of $\mathrm{Bn}^{\mathrm{dO}}-\mathrm{O}$-glycans to $\mathrm{Bn}^{\mathrm{d5}}$-O-glycans peaks. 
The mean RE $(3.10,3.99,2.00,3.48$ and $4.20 \%, n=3)$ was obtained, as listed in Table 1 . Five pairs of the Bn-O-glycans peaks were also presented CV value below $8 \%$ and RE value below $5 \%$, respectively (Table $1, n=3$ ), which are indicative of rather good precision and acceptable accuracy of the established method.

\section{Quali-quantitative profiling of Bn-O-glycans between $\mathrm{LO2}$ and SMMC-7721 cells}

The established IPMAL method has been applied to qualiquantitatively profiling of the repertoire $O$-glycans from normal human liver cell line L02 and human hepatoma cell line SMMC-7721. In parallel, L02 and SMMC-7721 cells were cultured with $\mathrm{Ac}_{3}$ GalNAc- $\alpha-\mathrm{Bn}^{\mathrm{d} 0}$ or $\mathrm{Ac}_{3}$ GalNAc- $\alpha-\mathrm{Bn}^{\mathrm{d} 5}$ precursor, respectively, and presented the MS-based quantitative results as illustrated in Fig. 4. As shown in Fig. 4, 9 and 10 Bn-O-glycans were observed in L02 and SMMC-7721 cells, respectively. The characterized structural details of these $\mathrm{Bn}-\mathrm{O}$ glycans were further identified by MS/MS, in consistent with the previous ref. 29, 37 and 38 One random MS/MS data of the two peaks with signals at $m / z 1043.33$ and $1346.33\left([\mathrm{M}+\mathrm{Na}]^{+}\right.$ adducts, from L02 cells) was illustrated in Fig. S4. $\dagger$

ESI-MS combined with MS/MS data has demonstrated that L02 cells amplified 9 Bn-O-glycans, one neutral Bn-O-glycans $\left([\mathrm{M}+\mathrm{Na}]^{+}\right.$ion peak with signal at $m / z$ 1043.33) and eight

Table 1 Linearity, reproducibility and accuracy evaluation of the IPMAL assay

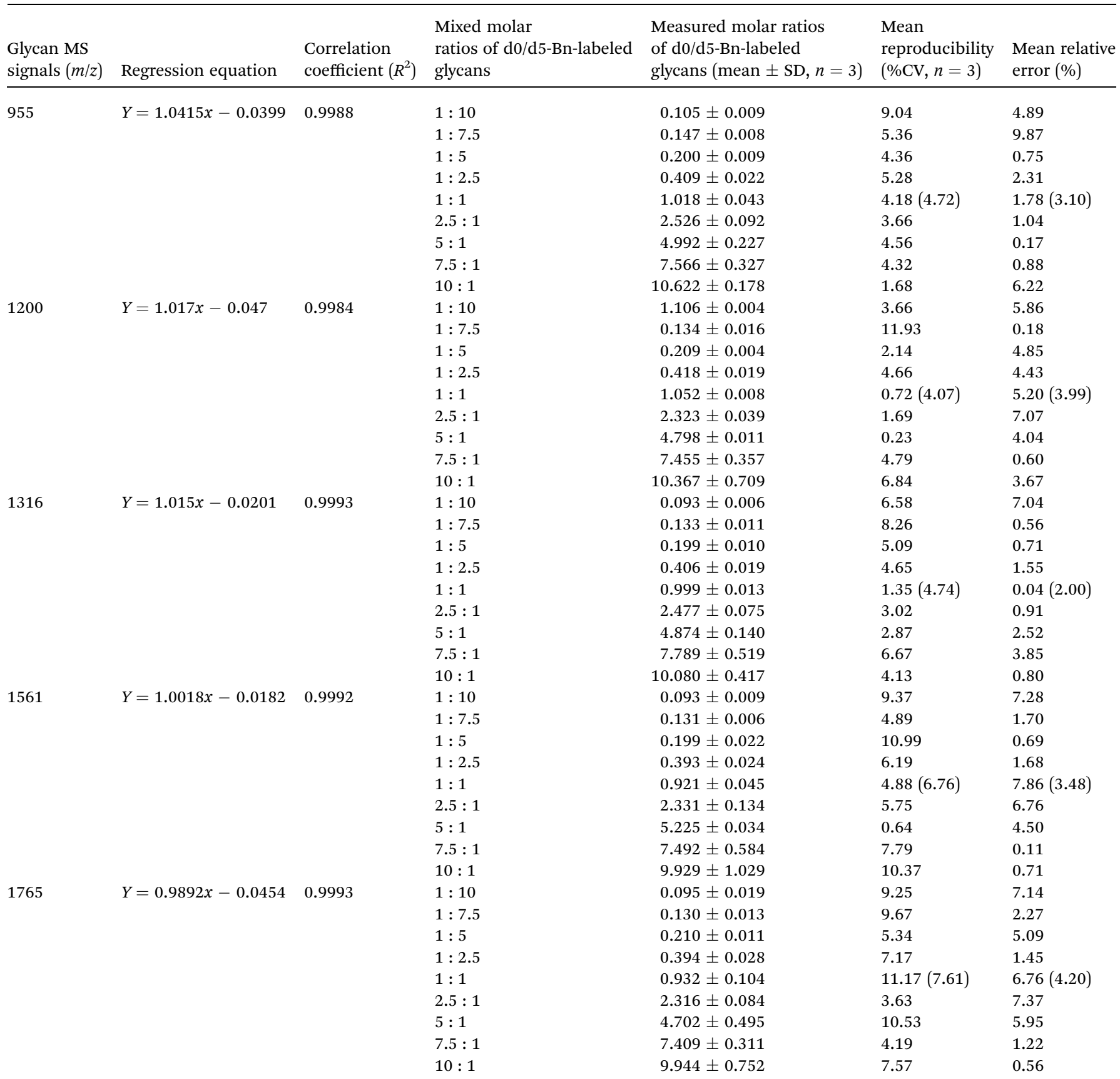



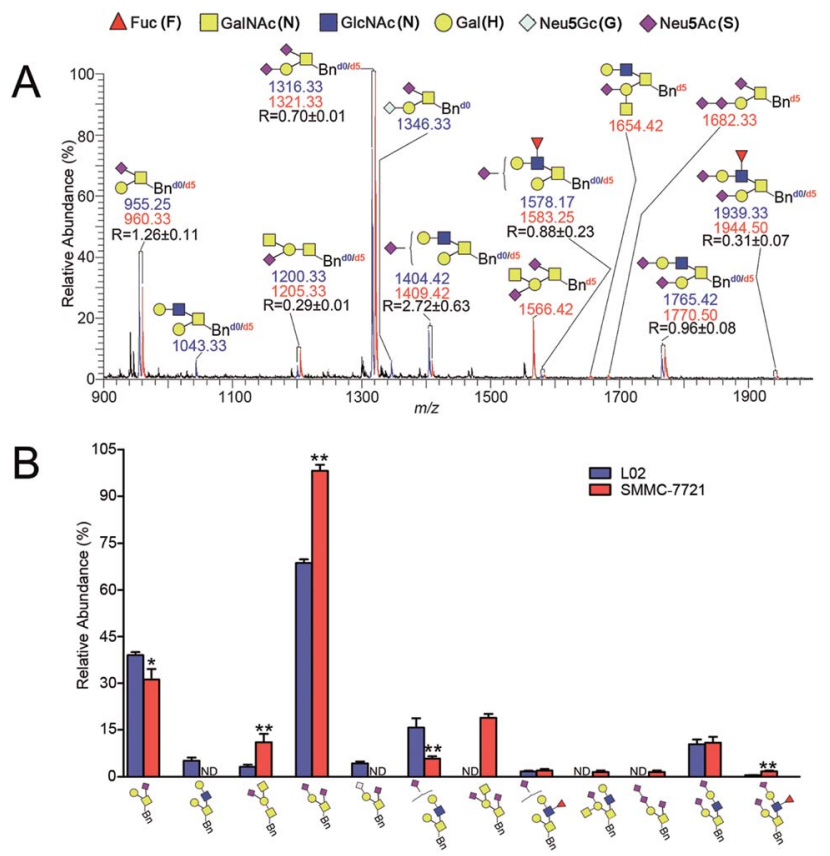

Fig. 4 (A) Quali-quantitative profiling of Bn-O-glycans between L02 and SMMC-7721 cells by ESI-MS and (B) bar charts derived from the relative intensities of the MS signals in (A). The intensity ratio of the $\mathrm{Bn}^{\mathrm{dO}}$-O-glycans to its corresponding $\mathrm{Bn}^{\mathrm{d} 5}-\mathrm{O}$-glycans is indicated as $R$ $(n=3$, averaged). Note: $* p<0.05, * * p<0.01$. Structure formulas: yellow square, $\mathrm{N}$-acetylgalactosamine (GalNAc, N); blue square, $\mathrm{N}$ acetylglucosamine (GlcNAc, N); yellow circle, galactose (Gal, H); red triangle, fucose (Fuc, F); purple diamond, sialic acid (Neu5Ac, S); white gray diamond, sialic acid (Neu5Gc, G).

sialylated Bn-O-glycans $\left([\mathrm{M}+\mathrm{Na}]^{+}\right.$adducts with signals at $\mathrm{m} / \mathrm{z}$ 955.25, 1200.33, 1316.33, 1346.33, 1404.42, 1578.17, 1765.42 and 1939.33), as shown in Fig. 4. Whereas, SMMC-7721 expressed $10 \mathrm{Bn}-\mathrm{O}$-glycans $\left([\mathrm{M}+\mathrm{Na}]^{+}\right.$adducts with signals at $\mathrm{m} / \mathrm{z}$ 960.33, 1205.33, 1321.33, 1409.42, 1566.42, 1583.25, 1654.42, 1682.33, 1770.50 and 1944.50), which were either high sialylated or fucosylated ones as later confirmed by MS/MS. In Fig. 4, seven pairs of $O$-glycan peaks with a 5 Da difference including $\mathrm{m} / \mathrm{z}$ 955.25/960.33, 1200.33/1205.33, 1316.33/1321.33, $1404.42 / 1409.42, \quad 1578.17 / 1583.25, \quad 1765.42 / 1770.50$ and 1939.33/1944.50, were observed in MS profile. From relative intensities signals in MS, the relative quantitation of these $O$ glycans in L02 and 7721 cells were indicated to be $R=1.26,0.29$, $0.70,2.72,0.88,0.96$ and 0.31 . Two single peaks with signals at $\mathrm{m} / \mathrm{z} 1043.33$ and 1346.33 were detected in L02 only, whereas three single $O$-glycan peaks with signals at $m / z 1566.42,1654.42$ and 1682.33 with high sialylation level, were observed in SMMC7721 cells only. Furthermore, based on relative abundance values of each pair of $O$-glycans peaks in MS, relative quantification of $O$-glycans between normal and tumor cells was achieved, as illustrated in Fig. 4B.

As shown in Fig. 4, O-glycans in SMMC-7721 cells with sugar compositions of N2H1S1, N1H1S2, N2H2F1S2 (molecular ion peaks $[\mathrm{M}+\mathrm{Na}]^{+}$with signals at $m / z 1205.33,1321.33$ and 1944.50) were significantly higher than those of L02 cells. Moreover, N2H2F1S1 and N2H2S2 $\left([\mathrm{M}+\mathrm{Na}]^{+}\right.$ion peaks with signals at $\mathrm{m} / \mathrm{z} 1583.25$ and 1770.50) was slightly higher than those of L02 cells. Fucosylated core $2 \mathrm{O}$-glycans were upregulated in SMMC-7721 cells. None of neutral $O$-glycan was observed in SMMC-7721 cells. Data indicated that SMMC-7721 express more $O$-glycans and higher levels of sialylated and/or fucosylated $O$-glycans over that of normal cell line L02, in line with the facts that abnormal sialylated and fucosylated $O$ glycans in biological processes were closely related to the occurrence, development and deterioration of liver tumor..$^{35}$

\section{Quali-quantitative profiling and distinction of both neutral and sialylated Bn-O-glycans between L02 and SMMC-7721 cells}

Due to the biological importance of the glycan terminal sialylation associated with infection or disease development, it is important to establish novel and effective method for linkagespecific distinction of sialic acids. Despite sialylated Bn-Oglycans can be successfully determined by ESI-MS, it is very challenging to assign sialic acids specific linkages by ESI-MS and/or MS/MS, as presented in Fig. 2B, S3 and S4 (ESI $\dagger$ file). Fortunately, a linkage-specific assignation of $O$-glycans terminal sialic acid could be achieved by combining our IPMAL assay with sialic acid derivatization (a mild dimethylamidation and permethylation), which could selectively convert $\alpha 2,6$-linked sialic acids to dimethylamidation and $\alpha 2,3$-linked sialic acid to lactones, as shown in Fig. S2.†

To ensure the feasibility of the assay, standard sialylated trisaccharides, $\alpha 2,3-\mathrm{Neu} 5 \mathrm{Ac}-\mathrm{Lac}\left(3^{\prime}-\mathrm{SL}\right)$ and $\alpha 2,6-\mathrm{Neu} 5 \mathrm{Ac}-\mathrm{Lac}$ (6'-SL), were submitted to the sialic acids specific derivatization and profiled by ESI-MS, as shown in Fig. S5 (ESI $\dagger$ file). According to the structural changes of glycans with sialic acid ends after the specific derivatization reactions, a mass difference ( $13 \mathrm{Da}$ ) between $\alpha 2,3$ - and $\alpha 2,6$-sialic acid can be detected, facilitating the isomeric assignment of $\alpha 2,3-$ and/or $\alpha 2,6$-sialylated glycans. As we expected, distinct $[\mathrm{M}+\mathrm{Na}]^{+}$ionized peaks at $\mathrm{m} / \mathrm{z} 838$ and $851(13 \mathrm{Da})$ were assigned to be $3^{\prime}$-SL and $6^{\prime}$-SL, respectively, demonstrating the feasibility of the assay for linkage specific characterization of glycan isomers with $\alpha 2,3-$ and $\alpha 2,6$-sialic acid ends.

We further applied our IPMAL method combined with sialic acids specific derivatization to achieve quali-quantitative profiling and distinction of both neutral and sialylated Bn-Oglycans between L02 and SMMC-7721 cells. After combining the IPAML assay with sialic acid derivatization, not only the sialic acids residues at $O$-glycans in L02 and SMMC-7721 were further stabilized, but also the linkage specificity as well as the relative quantitation could be well characterized, as shown in Fig. 5 .

Compared with the relative intensity of Bn-O-glycans in L02 and SMMC-7721 (Fig. 4A) in MS, MS signals at $\mathrm{m} / \mathrm{z}$ 955.33/ 960.33, 1043.42, 1200.50/1205.42, 1316.42/1321.42, 1404.42/ $1409.42,1566.50,1654.42,1765.58 / 1770.58$ and 1939.67/ $1944.67\left([\mathrm{M}+\mathrm{Na}]^{+}\right.$ion peaks) did not change, indicating the presence of neutral or sialylated Bn-O-glycans with $\alpha 2,3$-linked sialic acid (Neu5Ac), as shown in Fig. 5A. Whereas, Bn-O-glycans with $\alpha 2,6$-linked sialic acid (Neu5Ac) terminals yielded a $13 \mathrm{Da}$ mass increase. For example, peaks at $\mathrm{m} / \mathrm{z}$ 955.25/960.33, 1316.33/1321.33, 1566.42 and 1682.33, in Fig. 4A were shifted 

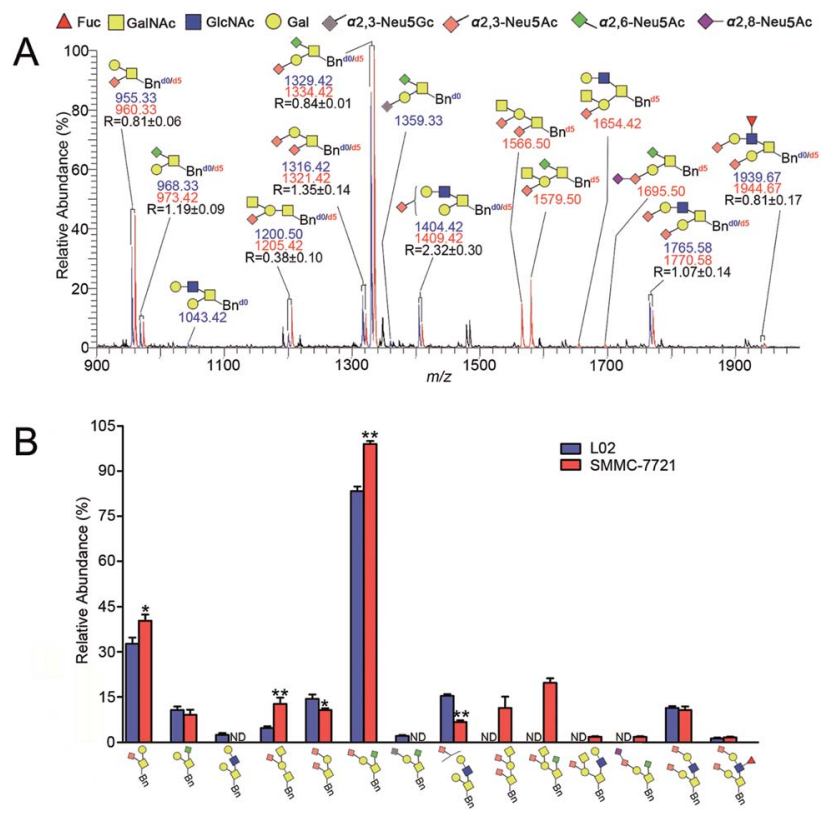

Fig. 5 (A) Quali-quantitative profiling and distinction of both neutral and sialylated $\mathrm{Bn}-\mathrm{O}$-glycans between LO2 and SMMC-7721 cells and (B) bar charts derived from the relative intensities of the MS signals in (A). The intensity ratio of the $\mathrm{Bn}^{\mathrm{dO}}-\mathrm{O}$-glycans to its corresponding $\mathrm{Bn}^{\mathrm{d} 5}-\mathrm{O}$-glycans is indicated as $R\left(n=3\right.$, averaged). Notes: ${ }^{*} p<0.05$; $* * p<0.01$. Structure formulas: yellow square, $N$-acetylgalactosamine (GalNAc); blue square, $N$-acetylglucosamine (GlcNAc); yellow circle, galactose (Gal); red triangle, fucose (Fuc); gray diamond, $\alpha 2,3-$ Neu5Gc; pink diamond, $\alpha 2,3-N e u 5 A c$; green diamond, $\alpha 2,6-N e u 5 A c$; purple diamond, $\alpha 2,8-\mathrm{Neu} 5 \mathrm{Ac}$.

to $\mathrm{m} / \mathrm{z} 968.33 / 973.42,1329.42 / 1334.42,1579.50$ and 1695.50 in Fig. 5A, suggesting the presence of $\alpha 2,6$-sialylated $O$-glycans. MS signal at $m / z 1359.33$ was assigned to be $O$-glycan with a $\alpha 2,3-$ linked sialic acid (Neu5Gc) and a $\alpha 2,6$-linked sialic acid (Neu5Ac). Structural details of all other peaks, including neutral, di- and tri-sialylated $O$-glycans have been determined by $\mathrm{MS} / \mathrm{MS}$, providing the proposed information of $O$-glycans terminal sialic acids linkage specificity, as shown in Fig. 5A. The quali-quantitative profiling and distinction of both neutral and sialylated Bn-O-glycans with linkage-specificity was indicated in Fig. 5B. As shown in Fig. 5B, $8 \mathrm{O}$-glycans were up-expressed in SMMC-7721 cells, while $4 \mathrm{O}$-glycans were down-expressed in L02 cells. Moreover, most of the up-expressed $O$-glycans are highly sialylated. The expression level of specific $O$-glycans such as the disialyl core 1 Neu5Ac- $\alpha-2,3-G a l-\beta-1,3-(N e u 5 A c-\alpha-2,6)-G a l N A c-\alpha-$ $O$-Thr in SMMC-7721 cells was higher over that of L02 cells, in line with the previous works. ${ }^{8,35}$ Therefore, the good compatibility of our IPMAL assay with sialic acid derivatization (a mild dimethylamidation and permethylation), shows great potential in quali-quantitative determination of the $O$-glycans with or without sialic acids between normal and disease.

\section{Conclusions}

An innovative and effective approach termed as IPMAL for quali-quantitative profiling of neutral and sialylated $\mathrm{Bn}-\mathrm{O}$ glycans by ESI-MS in positive-ion mode has been developed. The "light" and "heavy" $O$-glycan precursors could be chemically synthesized by one-step $O$-glycosylation, which shows methodological advantage over previous work and will make easy generalization and wide application of the established assay. Through metabolic oligosaccharide engineering and isotopic labeling, the MS-based quali-quantitative profiling of $\mathrm{Bn}-\mathrm{O}$ glycans derived from two cells could be achieved simultaneously through the mass differences $(5 \mathrm{Da})$ in pairs of peaks in MS. The quantitation feasibility, reproducibility, reliability and linearity of this strategy were fully investigated, yielding 100 fold linear dynamic range, good reproducibility (CV, 4.07-7.61\%) and accuracy (RE, 2-4.2\%). The quali-quantitative determination of Bn-O-glycans from L02 and SMMC-7721, were achieved successfully, which is beneficial for the mechanism elucidation of $O$-glycosylation as required in clinical and pathological research.

When the IPAML approach was combined with sialic acid specific derivatization, quali-quantitative determination of neutral and sialylated $O$-glycans terminal sialic acids with $\alpha 2,3-$ and/ $\alpha 2,6$-linkages based on MS profile could be accomplished the first time. The proposed assay has been successfully applied to quali-quantitative profiling and sialic acid linkage specific discrimination of the whole $O$-glycans derived from L02 and SMMC-7721 cell. As the total sialic acids expression level as well as their linkage specificity could be used to predict the risk of various diseases such as tumor, the proposed assay which facilitates quali-quantitatively profiling the whole $O$-glycans especially sialylated ones, shows great potential for clinical biomarker discovery.

In addition, the method with the merits of bypassing the releasing and relabeling of the glycan, affording the Mucin-type $O$-glycan itself with chromophore group, which not only improves the detection sensitivity of mass spectrometry, but also enables the further HPLC and LC-MS separation analysis. The proposed method can also be applied to comprehensive screening meaningful $O$-glycans from clinical samples such as tissue.

The method is effective and highly reproducible. With all the merits described above, we believe this method will make significant contribution to glycomics.

The excellent applicability of the suggested procedure was validated via quantitative comparison of the $O$-glycans of perch and salmon eggs by ESI-MS and RP-HPLC-UV-ESI-MS/MS.

\section{Conflicts of interest}

There are no conflicts to declare.

\section{Acknowledgements}

This work was funded by National Natural Science Foundation (No. 31300678, 31370804, 21375103 and 31670808), the Scientific Research Program Fund for Shaanxi Province Key Laboratory (14JS101), Shaanxi Basic Research Program of Natural Science (2016JQ3018), Outstanding Youth Backbone of Northwest University and Graduate Innovation Fund (YZZ17163 and YZZ15067). 


\section{Notes and references}

1 L. A. Tabak, Semin. Cell Dev. Biol., 2010, 21, 616-621.

2 D. T. Tran and K. G. Ten Hagen, J. Biol. Chem., 2013, 288, 6921-6929.

3 M. R. Kudelka, T. Ju, J. Heimburg-Molinaro and R. D. Cummings, Adv. Cancer Res., 2015, 126, 53-135.

4 S. Yang, E. Jankowska, M. Kosikova, H. Xie and J. Cipollo, Anal. Chem., 2017, 89, 9508-9517.

5 T. Nishikaze, H. Tsumoto, S. Sekiya, S. Iwamoto, Y. Miura and K. Tanaka, Anal. Chem., 2017, 89, 2353-2360.

6 D. H. Dube and C. R. Bertozzi, Nat. Rev. Drug Discovery, 2005, 4, 477-488.

7 A. L. Lewis and W. G. Lewis, Cell Microbiol., 2012, 14, 11741182.

8 E. V. Chandrasekaran, J. Xue, J. Xia, R. D. Locke, S. A. Patil, S. Neelamegham and K. L. Matta, J. Proteome Res., 2012, 11, 2609-2618.

9 C. B. Madsen, K. Lavrsen, C. Steentoft, M. B. VesterChristensen, H. Clausen, H. H. Wandall and A. E. Pedersen, PLoS One, 2013, 8, e72413.

10 S. Chugh, V. S. Gnanapragassam, M. Jain, S. Rachagani, M. P. Ponnusamy and S. K. Batra, Biochim. Biophys. Acta Rev. Canc., 2015, 1856, 211-225.

11 T. Ju, Y. Wang, R. P. Aryal, S. D. Lehoux, X. Ding, M. R. Kudelka, C. Cutler, J. Zeng, J. Wang, X. Sun, J. Heimburg-Molinaro, D. F. Smith and R. D. Cummings, Proteomics: Clin. Appl., 2013, 7, 618-631.

12 K. J. Kim, Y. W. Kim, Y. G. Kim, H. M. Park, J. M. Jin, Y. Hwan Kim, Y. H. Yang, J. Kyu Lee, J. Chung, S. G. Lee and A. Saghatelian, Biotechnol. Prog., 2015, 31, 840-848.

13 L. R. Ruhaak, G. Xu, Q. Li, E. Goonatilleke and C. B. Lebrilla, Chem. Rev., 2018, 118, 7886-7930.

14 M. J. Bowman and J. Zaia, Anal. Chem., 2007, 79, 5777-5784.

15 Y. Xie, J. Liu, J. Zhang, J. L. Hedrick and C. B. Lebrilla, Anal. Chem., 2004, 76, 5186-5197.

16 G. Alvarez-Manilla, N. L. Warren, T. Abney, J. Atwood III, P. Azadi, W. S. York, M. Pierce and R. Orlando, Glycobiology, 2007, 17, 677-687.

17 P. Kang, Y. Mechref, Z. Kyselova, J. A. Goetz and M. V. Novotny, Anal. Chem., 2007, 79, 6064-6073.

18 C. Wang, P. Zhang, W. Jin, L. Li, S. Qiang, Y. Zhang, L. Huang and Z. Wang, J. Proteomics, 2017, 150, 18-30.
19 M. R. Kudelka, A. V. Nairn, M. Y. Sardar, X. Sun, E. L. Chaikof, T. Ju, K. W. Moremen and R. D. Cummings, Glycobiology, 2018, 28, 214-222.

20 P. H. Jensen, D. Kolarich and N. H. Packer, FEBS J., 2010, 277, 81-94.

21 X. You, H. Qin and M. Ye, J. Sep. Sci., 2018, 41, 248-261.

22 J. Furukawa, N. Fujitani and Y. Shinohara, Biomol. Ther., 2013, 3, 198-225.

23 S. Sekiya, Y. Wada and K. Tanaka, Anal. Chem., 2005, 77, 4962-4968.

24 M. Toyoda, H. Ito, Y. K. Matsuno, H. Narimatsu and A. Kameyama, Anal. Chem., 2008, 80, 5211-5218.

25 H. Nie, Y. Li and X. L. Sun, J. Proteomics, 2012, 75, 3098-3112. 26 E. Casal, R. Lebron-Aguilar, F. J. Moreno, N. Corzo and J. E. Quintanilla-Lopez, Rapid Commun. Mass Spectrom., 2010, 24, 885-893.

27 Y. Zhang, B. Wang, W. Jin, Y. Wen, L. Nan, M. Yang, R. Liu, Y. Zhu, C. Wang, L. Huang, X. Song and Z. Wang, Anal. Chim. Acta, 2019, 1048, 105-114.

28 K. Jiang, H. Zhu, L. Li, Y. Guo, E. Gashash, C. Ma, X. Sun, J. Li, L. Zhang and P. G. Wang, Anal. Chim. Acta, 2017, 981, 53-61.

29 M. R. Kudelka, A. Antonopoulos, Y. Wang, D. M. Duong, X. Song, N. T. Seyfried, A. Dell, S. M. Haslam, R. D. Cummings and T. Ju, Nat. Methods, 2016, 13, 81-86.

30 P. Kang, Y. Mechref, I. Klouckova and M. V. Novotny, Rapid Commun. Mass Spectrom., 2005, 19, 3421-3428.

31 I. Ciucanu and C. E. Costello, J. Am. Chem. Soc., 2003, 125, 16213-16219.

32 D. Frem, D. Urban, S. Norsikian and J.-M. Beau, Eur. J. Org. Chem., 2017, 2017, 5094-5101.

33 R. Sommer, D. Hauck and A. Titz, ChemistrySelect, 2017, 2, 4187-4192.

34 J.-M. Beau, F.-D. Boyer, S. Norsikian, D. Urban, B. Vauzeilles and A. Xolin, Eur. J. Org. Chem., 2018, 2018, 5795-5814.

35 Y. Zhang, W. Zhao, Y. Zhao and Q. He, Glycoconjugate J., 2015, 32, 39-47.

36 H. Li, W. Gao, X. Feng, B. F. Liu and X. Liu, Anal. Chim. Acta, 2016, 924, 77-85.

37 P. Babu, S. J. North, J. Jang-Lee, S. Chalabi, K. Mackerness, S. R. Stowell, R. D. Cummings, S. Rankin, A. Dell and S. M. Haslam, Glycoconjugate J., 2009, 26, 975-986.

38 J. P. Zanetta, V. V. Gouyer, E. Maes, A. Pons, B. Hemon, A. Zweibaum, P. Delannoy and G. Huet, Glycobiology, 2000, 20, 565-575. 